\title{
IMPLEMENTAÇÃO DA FERRAMENTA FMEA DE PROCESSO NA INDÚSTRIA AERONÁUTICA
}

\author{
L.C. Pereira ${ }^{1}$ \\ 1 Faculdade de Tecnologia de São José dos Campos - Professor Jessen Vidal \\ Av. Cesare Mansueto Giulio Lattes, 1350 - Eugênio de Melo, São José dos Campos/SP, \\ CEP.: 12247-014, Brasil. \\ Telefone: (12) 3905-2423
}

\begin{abstract}
RESUMO: O setor aeronáutico sempre teve como premissa que os produtos de fornecedores tivessem alto grau de maturidade, tendo requisitos como testes de maturidade e de qualificação. Porém, ambos não tratavam das não conformidades, restando a necessidade de troca das peças rejeitadas, ocasaionando parada da linha fabril. Tendo referência o cenário automotivo e seu alto controle de maturidade, a empresa Alfa decidiu por empregar o PPAP (Production Part Approval Process) em seus fornecedores, afim de diminuir essas não conformidades. Um destes deliverables é o FMEA de Processo, no qual a Qualidade é responsável por avaliar e assegurar que o processo fabril do fornecedor tenha conhecimento dos modos de falha de seu processo e que impeça que itens rejeitados sejam enviados ao cliente. Esta monografia visa apresentar a aplicação diferenciada do PFMEA em forma de cobrança, avaliação, ganhos de processo, lessons learned, e por fim, payback dessa ferramenta para a empresa Alfa.
\end{abstract}

\section{PALAVRAS-CHAVE: PPAP, FMEA, Modos de Falha.}

ABSTRACT: The aviation industry has always had as premise that the products of their suppliers had a high degree of maturity, and for this, requirements of maturity and qualification tests were required. But both did not treat the non-conformities routine, leaving only the need to exchange request of rejected parts, which led to stop the production line. Thus, with reference to the automotive scene and its high control of maturity, the Brazilian aeronautics company Alfa decided to use the PPAP (Production Part Approval Process) on its suppliers in order to reduce these nonconformities within the same. One of these deliverables is the Process FMEA, in which the Quality is responsible for assessing and ensure that the manufacturing vendor process has full knowledge of the failure modes of your process and that prevents rejected items are sent to the client. This monograph aims to present the differentiated application of PFMEA in its form of charge, assessment, process gains and lessons learned, and finally payback of this tool for Alfa company.

KEYWORDS: PPAP; FMEA; Failure Modes.

\section{INTRODUÇÃO}

No mundo atual, uma empresa que se dedica a produzir com menos desperdício de material e principalmente reduzindo os custos da não qualidade, faz a diferença perante o mercado.

A empresa aeronáutica brasileira Alfa estava passando por um caso de redução dos custos pela não qualidade, envolvendo fornecedor e processos internos. Porém, as especificações existentes para esse tipo de produto são limitadas, mas ao mesmo tempo necessárias.

Logo, com base em projetos anteriores, foram levantados todos os problemas ocorridos e que poderiam ser sanados ainda na fase de desenvolvimento de novas aeronaves (lições aprendidas). $\mathrm{O}$ problema era desenvolver uma ferramenta de uso externo (fornecedor) e interno que minimizasse 
essas ocorrências, mas acima de tudo, que fosse viável no controle de não conformidades e quando ocorressem, que fosse rapidamente definida uma estratégia de controle e mitigação para que não impactasse na fabricação e entrega das aeronaves aos clientes.

Com base nisso, esta empresa buscou uma ferramenta conhecida da área automobilística, o PPAP (Production Part Approval Process) ou simplesmente o Processo de Aprovação do Produto e Processo. Essa ferramenta era constituída de várias outras que individualmente tratavam de alguma particularidade do processo fabril ainda na sua concepção até seu desenvolvimento seriado. Logo, essa ferramenta foi absorvida por essa empresa aeronáutica que passou a aplicá-la em sua cadeia produtiva e ainda, requisitá-la nos fornecedores.

Uma vez estudada a ferramenta, foram geradas as documentações e/ou evidências a serem requisitadas para os fornecedores e internamente, como necessidade de controle do processo produtivo no desenvolvimento de novas aeronaves. Essas ferramentas a serem requisitadas pelo PPAP da empresa Alfa são: DFMEA (Design FMEA), Layout, Fluxograma de Processo, PFMEA (Process FMEA), Plano de Controle, Análise de Sistemas de Medição (MAS - Measurement System Analysis), Estudo de Capabilidade de Processo, Ferramentais, Gages e Fixtures, Critérios de Aceitação Visual, Relatório Dimensional, Relatório de Materiais, Processos Especiais (conf. AS9102), Gerenciamento da Cadeia de Subfornecedores, Material Composto (FPQ), Teste de Vida Acelerada (ALT), Teste de Screening (HASS), Procedimento de testes funcionais (ATP), Embalagem e Capacidade produtiva.

Os itens acima seriam requisitados em diferentes fases e em níveis de informação diferentes, com base nas fases de desenvolvimento da aeronave. Mas qual dessas ferramentas seria ideal para redução das não conformidades existentes constantemente nos fornecedores e internos, hoje responsáveis pela demora na entrega de aeronaves e definição de solução das mesmas, atacando a causa raiz e não somente a falha superficialmente? A resposta é a FMEA, mais precisamente a PFMEA ou FMEA de Processo.

A Metodologia de Análise do Modo e Efeito de Falha, conhecida como FMEA (do inglês Failure Mode and Effect Analysis), é uma ferramenta que busca, em princípio, evitar, por meio da análise das falhas potenciais e propostas de ações de melhoria, que ocorram falhas no projeto do produto ou do processo, buscando também aumentar a confiabilidade para os consumidores, visto que a falha de um produto causa aos seus consumidores insatisfação ao abster-se do uso do seu produto. Conforme descrito por Silva (2005), sob o ponto de vista de alguns autores, a FMEA é tratado como método, já no ponto de vista de outros é chamado de ferramenta. E tem um terceiro grupo de pessoas que o descreve como técnica de estudos de confiabilidade e classifica a FMEA como o método ou técnica que mais se expandiu em termos de análise de confiabilidade.

Segundo Cassanelli et al. e Aguiar e Mello (2008), a FMEA é uma técnica para análise de um sistema, onde são identificados os potenciais modos de falha, as causas e os efeitos. A análise desta ferramenta deve ser feita no período de desenvolvimento para que o modo de falha tenha o efeito desejado.

Palady (1997) assegura que a FMEA é um procedimento de risco reduzido, porém sua efetividade em relação a custos é elevada baseando-se na prevenção de problemas e definição de soluções.

Para evitar imprevistos é necessário que seja feita a identificação dos problemas antes que eles cheguem a existir, a FMEA propicia este efeito ao localizar as falhas. Porém, conforme mencionado por Aguiar e Mello (2008), existem locais onde a FMEA é empregado apenas para atender requisitos normativos, ao invés de dispor de seus ganhos, o que pode acarretar em uso incorreto.

Zorzan et al. (2013) e Leal et al. (2006) definem a análise da FMEA como um instrumento da qualidade que tem como propósito identificar e analisar falhas que poderão vir a existir em um 
processo, projeto, serviço ou sistema, para que sejam estabelecidas ações que deverão ser colocadas em prática para aniquilar ou, pelo menos, diminuir estas falhas, antes que elas impactem o cliente.

Atualmente a FMEA pode ser aplicada em dois grupos distintos, sendo eles o de desenvolvimento do projeto do produto ou como o de processo.

A FMEA de produto visa diagnosticar as falhas que poderão ocorrer com o produto dentro das especificações do projeto, já na FMEA de processo são consideradas as falhas no planejamento e execução do processo, ou seja, a finalidade desta análise é evitar equívocos do processo, tendo como base as não conformidades do produto com as especificações do projeto.

A FMEA pode ser aplicada nas seguintes situações:

- Na fase de projeto de sistemas visando detectar possíveis falhas e melhorar a confiabilidade do sistema;

- Na revisão de segurança de sistemas e unidades em operação procurando verificar a propagação das falhas sobre os outros componentes do sistema e as implicações para a segurança das instalações;

- Para diminuir a chance de falhas potenciais (ou seja, que ainda não tenham ocorrido) em produtos/processos já em operação;

A base para a aplicação da FMEA é um formulário, que segue os mesmos princípios para ambos os tipos de FMEA e sua aplicação, isto é, se é FMEA de produto, processo ou procedimento e se é aplicado para produto/processos novos ou já em operação.

A análise consiste basicamente na formação de um grupo de pessoas que identificam para o produto/processo em questão suas funções, os tipos de falhas que podem ocorrer, os efeitos e as possíveis causas desta falha. Em seguida são avaliados os riscos de cada causa de falha por meio de índices e, com base nesta avaliação, são tomadas as atitudes necessárias para diminuir estes riscos, aumentando a confiabilidade do produto/processo. É importante ressaltar, que a análise FMEA é muito mais do que apenas preencher um formulário, o seu verdadeiro valor está na discussão e reflexão dos membros do grupo sobre as falhas potenciais do produto/processo e as ações de melhoria propostas pelo grupo.

Existem basicamente cinco etapas para a aplicação da FMEA:

\subsection{Planejamento}

Esta fase é realizada pelo responsável pela aplicação da metodologia e compreende na descrição das metas e abrangência da análise, onde localizam quais produtos/processos serão avaliados.

O planejamento também se emprega na formação dos grupos de trabalho (entre 4 a 6 pessoas) e multidisciplinar (contando com pessoas de diversas áreas como qualidade, desenvolvimento e produção). As reuniões devem ser agendadas com antecedência e com o consentimento de todos os participantes para evitar paralizações.

\subsection{Análise de Falhas em Potencial}

Esta fase é executada pelo grupo de trabalho que discute e preenche o formulário FMEA, definindo: funções e características do produto/processo, tipos de falhas potenciais para cada função, efeito do tipo de falha, possíveis causas da falha e controles atuais.

\subsection{Avaliação dos Riscos}

Esta fase é definida pelo grupo os índices de severidade (S), ocorrência (O) e detecção (D) para cada causa de falha, de acordo com critérios previamente.

\subsection{Melhoria}

Nesta etapa o grupo utiliza os seus conhecimentos e sua criatividade, e devem tomar alguns tipos de medidas, como por exemplo: medidas de prevenção total ao tipo de falha, medidas de 
prevenção total de uma causa de falha, medidas que dificultam a ocorrência de falhas, medidas que impedem o efeito do tipo de falha, medidas que aumentam a probabilidade de detecção do tipo ou da causa de falha.

\subsection{Continuidade}

O formulário preenchido de FMEA, uma vez realizada uma análise para um produto/processo qualquer, deve ser revisado sempre que ocorrerem alterações neste produto/processo específico. Mesmo que não haja alterações deve-se regularmente revisar a análise confrontando as falhas potenciais imaginadas pelo grupo com as que realmente vêm ocorrendo no dia-a-dia do processo e uso do produto, de forma a permitir a incorporação de falhas não previstas, bem como a reavaliação, com base em dados objetivos, das falhas já previstas pelo grupo.

A metodologia FMEA é importante porque pode proporcionar para a empresa: a facilidade de aplicação do método, a identificação de todas as possibilidades de ocorrência de falhas simples de cada item do sistema e a formulação de ações corretivas para eliminar ou reduzir as consequências das falhas.

\section{MATERIAL E MÉTODOS}

Neste capítulo serão abordados os métodos e processos utilizados para caracterizar a implementação da PFMEA na indústria aeronáutica, os dados coletados, a análise e discussão dos dados.

\subsection{Métodos e Instrumentos para Implementação da Ferramenta}

Para atingir o resultado esperado foi necessária à elaboração de Instruções de Trabalho, detalhando o modo correto de execução do novo processo, Planos de Controle contendo controles previstos nas operações listadas no Fluxograma de Processo e estabelecer características que devem ser verificadas, tanto quanto os métodos e o plano de reação em cada etapa listada, implementação da ferramenta SAP que é utilizada na tratativa e armazenamento das informações referentes às não conformidades e também foram realizadas sessões de brainstorming e reuniões para preenchimento do formulário PFMEA.

Foi imprescindível para o desenvolvimento da FMEA na empresa aeronáutica Alfa, avaliar os custos das não-conformidades e também como a fábrica e seus fornecedores se beneficiariam com os conhecimentos dos modos de falha de seu processo, fazer um levantamento da quantidade de peças que necessitavam ser trocadas e somente então, comparar todos os gastos envolvidos com o processo de inserção da PFMEA. Para levantar certos dados foram necessários acompanhamentos diretamente na fábrica, e também com representantes das áreas envolvidas e outros foram fornecidos pelo fornecedor.

\subsubsection{Instrução de Trabalho}

A instrução de trabalho (Figura 1) deve conter a forma correta de execução de determinada atividade dentro de um processo. Sua definição é simples, porém, deve ser feita por uma pessoa que conheça detalhadamente a atividade que deve ser descrita.

A Instrução de Trabalho deve seguir um passo a passo, pois esta instrução servirá como base para treinamentos aos colaboradores e para que se tenha um processo claro e objetivo. 


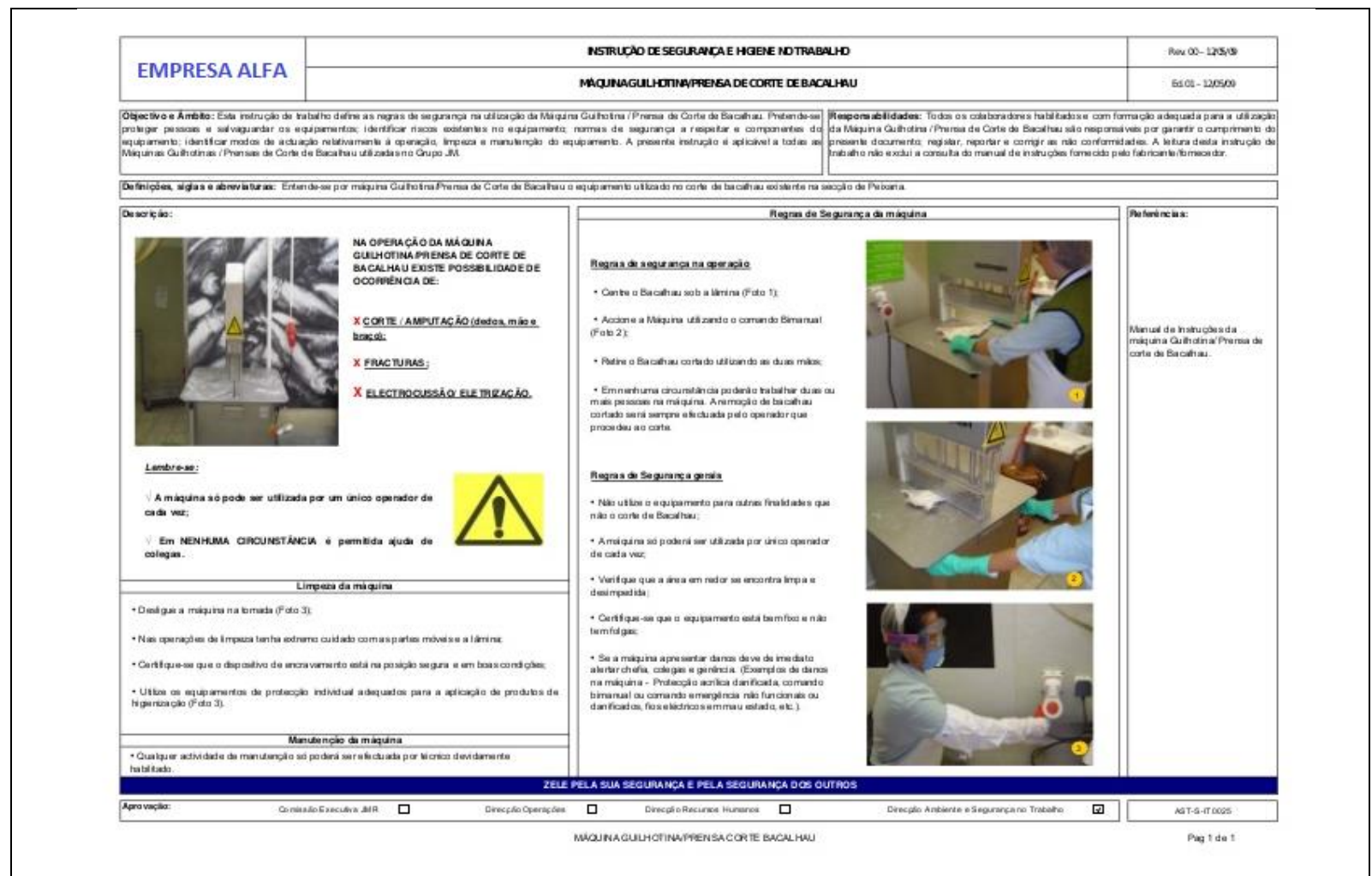

Figura 1. Representação da Instrução de Trabalho Fonte: Empresa Alfa (2019)

\subsubsection{Plano de Controle}

Um dos principais objetivos da implementação da ferramenta PFMEA é melhorar a qualidade e a confiabilidade do processo, assegurando maior satisfação dos clientes. Para que isso seja colocado em prática, deve-se ir além da emissão de relatórios e sua conservação, ou seja, devem ser analisados os controles previstos para o processo em questão e compreender o potencial dos controles na prevenção e detecção das causas e modos de falha.

No plano de controle (Figura 2) são descritos métodos de inspeção e quais as ferramentas utilizadas no processo para que este seja padronizado e que no caso de existir variações, elas sejam mínimas. O plano de controle não substitui as instruções de trabalho e tais documentos devem ser utilizados em conjunto, pois um complementa as informações contidas no outro.

Itens que necessitam ser controlados para garantir qualidade do produto:

- Controle de produto dos fornecedores;

- Capacidade do processo de fabricação;

- Controle estatístico de processo;

- Instruções de inspeção de testes laboratoriais;

- Testes de desempenho da engenharia. 


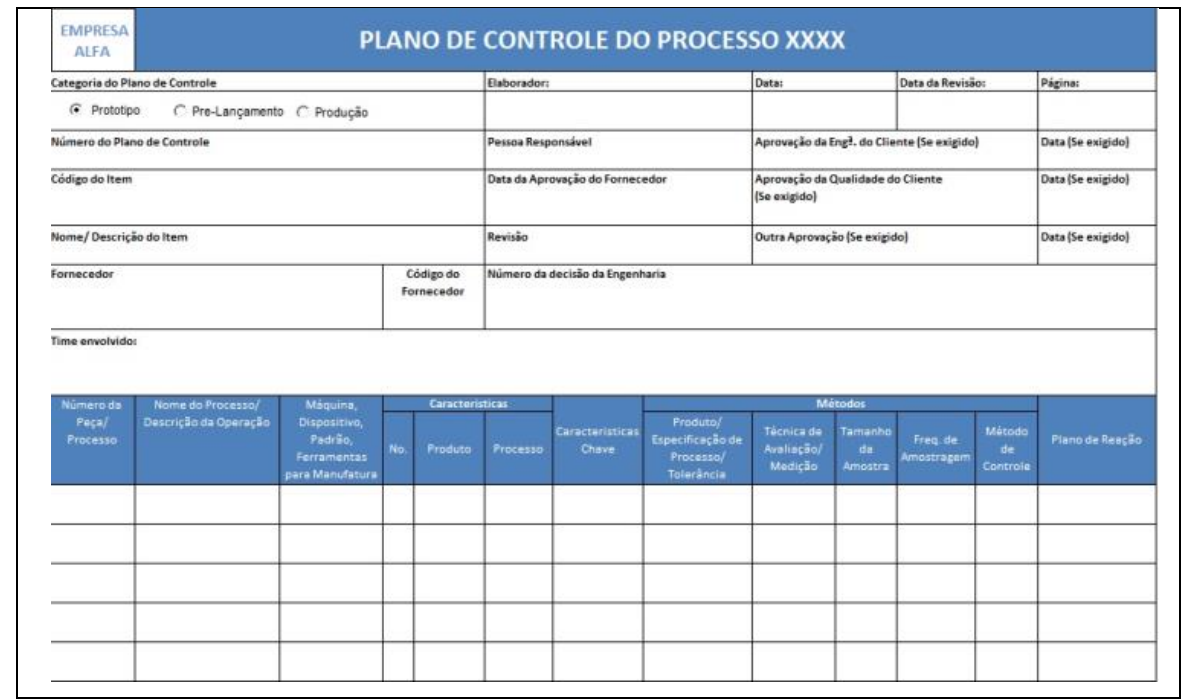

Figura 2. Representação de Plano de Controle

Fonte: Empresa Alfa (2019)

\subsubsection{Fluxograma de Processo}

O fluxograma (Figura 3) é uma ferramenta utilizada na empresa Alfa para conhecimento de todas as etapas dos processos realizados na empresa. No diagrama são exibidas, de forma sequencial, as diversas etapas, entradas e saídas que devem ser realizadas para obtenção de um produto final.

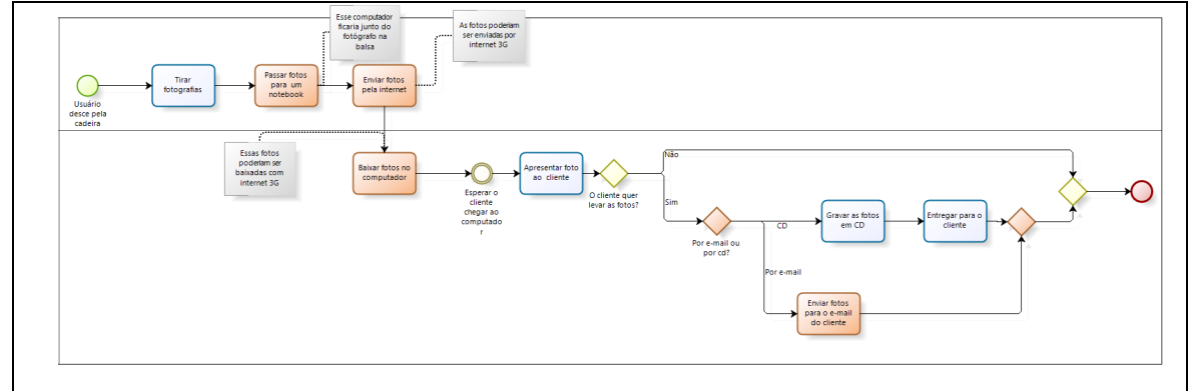

Figura 3. Representação de Fluxograma de Processo

Fonte: Empresa Alfa (2019)

\subsubsection{Brainstorming}

O brainstorming (Figura 4) é uma técnica que envolve a participação de várias áreas de uma mesma empresa e todos contribuem com ideias e soluções que surgem no momento para cada membro para resolução de um problema.

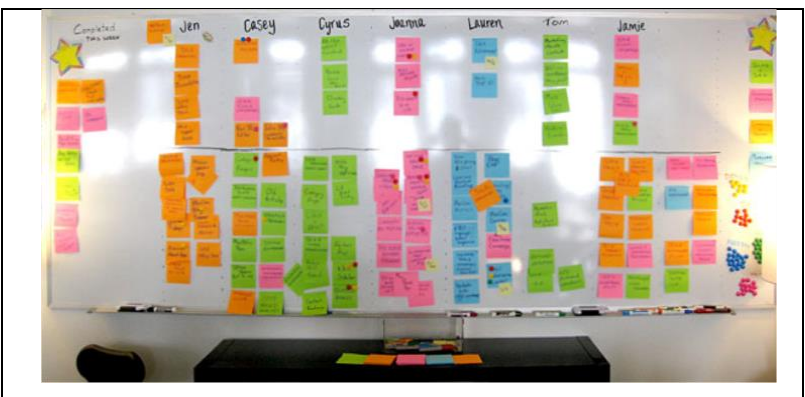

Figura 4. Representação de Brainstormig

Fonte: Empresa Alfa (2019) 


\section{ISSN $2447-5378$}

\subsubsection{Ferramenta SAP ERP}

O SAP ERP (Figura 5) é um sistema integrado de gestão empresarial transacional. O sistema contempla a empresa como um todo com a divisão por módulos e cada módulo corresponde a uma área específica. O SAP ERP é um servidor de banco de dados com um ou mais servidores, isso garante a integridade dos dados. Um dos dados que é armazenado no SAP ERP são as notas de não conformidade da empresa.

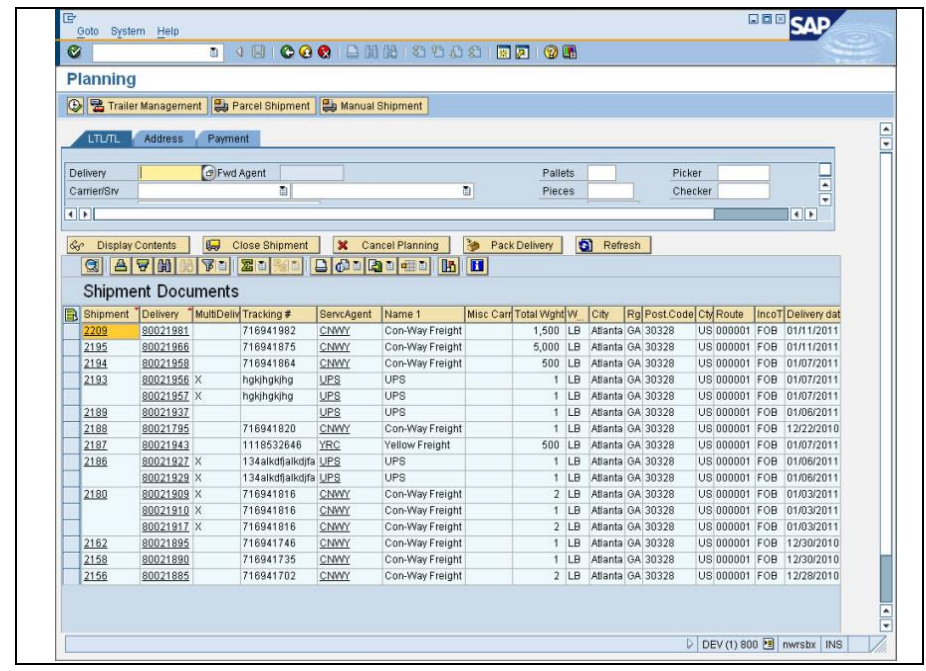

Figura 5. Representação de Brainstormig Fonte: Empresa Alfa (2019)

\subsubsection{Formulário PFMEA}

O formulário PFMEA deve ser preenchido durante as reuniões com o time designado. A figura 6 demonstra um exemplo do formulário utilizado:

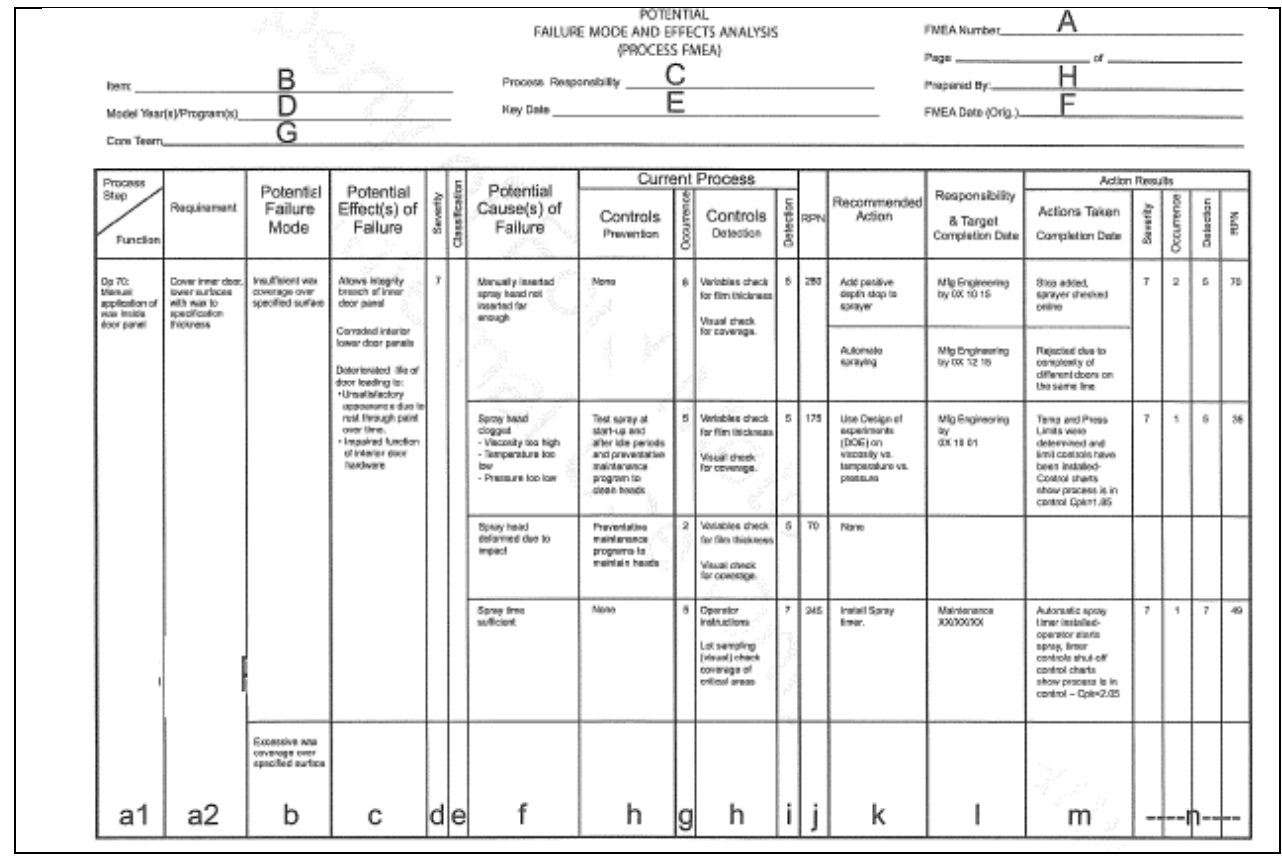

Figura 6. Representação de Brainstormig

Fonte: Empresa Alfa (2019) 
Algumas informações que devem ser preenchidas no formulário PFMEA: Número da FMEA (A), Item (B), Processo de Responsabilidade (C), Ano Modelo / Programa (D), Key Data (E), FMEA Data (F), Core Team (G), Elaboração (H), a1: Processo Função (a1), a2: Requisitos (a2), Modo de Falha Potencial (b), Efeito Potencial de falha (c), Severidade - S (d)e: Classificação (e)- esta coluna pode ser usado para destacar os modos de falha de alta prioridade ou causas que podem exigir uma avaliação adicional de engenharia; Causa Potencial de modo de falha (f), Ocorrência (g), Controles processo atual (h), Detecção (i), Risk Priority Number (j) Recomendado ações (k), Responsabilidade \& Target Data de Conclusão (1), Ação Leve e Data de Conclusão (m), Gravidade, Ocorrência, Detecção (n).

\subsection{Premissas de trabalho}

A empresa na qual ocorreu a implementação da ferramenta PFMEA se comprometeu a melhorar continuamente seus processos e a utilização desta ferramenta ajudou para atingir este objetivo.

Para que a PFMEA fosse implementada, foi necessário definir um líder que pertencia à área da qualidade. Porém, para que a implementação tivesse êxito, foi necessário reunir uma equipe de especialistas com experiência nas áreas afetadas e nos processos a serem analisados.

Assim, foram reunidos engenheiros de processo, de manufatura, montagem, assistência técnica, envolvendo também representantes da qualidade e dos fornecedores.

O momento de execução é um dos fatores mais importantes para a implementação com sucesso da ferramenta PFMEA. A PFMEA deve ser uma atividade que ocorre antes do processo ter sido incorporado ao produto, pois assim obtém melhores resultados.

O tempo utilizado no início do projeto para realização da PFMEA irá ser menor do que sem a utilização da ferramenta e contribui de maneira que quanto antes for detectado a falha mais facilmente podem ser implementadas alterações no processo e isso ocasiona menores custos e nãoconformidades menores.

A PFMEA sempre deve ser revisada ao menor detalhe alterado no processo, ou seja, é um documento dinâmico.

\subsection{Estudo de caso}

\subsubsection{Dificuldades na implementação da ferramenta PFMEA}

No processo de implementação da ferramenta PFMEA, verificaram-se os seguintes problemas:

- Repetição de informações antigas;

- Equipes não preparadas;

- Falta de tempo e vontade para lidar com o inesperado;

- Dados incompletos devido à dificuldade de preencher formulário;

- Falha na utilização de dados existentes.

Estas dificuldades associadas implicam na ocorrência de irregularidades na utilização da PFMEA, o que acabou gerando uma queda de eficiência em sua aplicação, comprometando os objetivos reais da utilização, que estão diretamente conectados aos pontos positivos de sua aplicação.

Para que fossem identificadas tais irregularidades, foram monitorados alguns grupos de análise de PFMEA, sendo que os grupos pertenciam a diferentes áreas e processos.

\subsubsection{Soluções}

A seguir, estão descritas soluções para resolução dos problemas detectados:

- Treinamento: planejamento de cursos para funcionários envolvidos, sua estrutura se baseia na revisão de técnicas e análises, seja no formato de brainstorming, gráfico de causa e efeito e desenvolvimento de um exemplo no próprio curso. Todos os funcionários envolvidos no desenvolvimento da PFMEA foram envolvidos. 
- Composição de nova equipe: O novo grupo de trabalho escolhido foi estabelecido de acordo com critérios como conhecimento sobre PFMEA, desempenho no treinamento oferecido, envolvimento no exemplo utilizado no treinamento. Integrantes escolhidos: almoxarifado, produção, métodos e processos, garantia da qualidade, engenharia de produto e controle da produção.

- Elaboração de nova planilha: Constatou-se que a primeira planilha elaborada possuía alguns equívocos. Assim, foi desenvolvida uma nova planilha juntamente com a nova equipe de trabalho.

\section{RESULTADOS E DISCUSSÃO}

Para se atingir os resultados esperados foi necessário definir o contexto da PFMEA, o processo que seria analisado e os objetivos do processo que foram identificados a partir do fluxograma de processo seguido por uma análise de tarefas.

Também foi necessário reunir uma equipe, definindo líder, quem faria parte da equipe sendo que esta deveria conter membros de áreas diversas envolvidos no processo escolhido para a análise.

Após a definição da equipe e horários para brainstormig e reuniões, a equipe se reuniu para definir os modos de falha potencial nos processos, incluindo problemas, preocupações e oportunidades de melhoria.

A equipe também identificou os efeitos, descrevendo as consequências de falhas seja no sistema, peça, processo, entre outros.

E identificaram também a causa raiz que está na origem do modo de falha.

\subsection{Redefinição das etapas de trabalho}

Após a primeira tentativa de desenvolvimento do PFMEA se constatou que era necessária uma nova definição das etapas do processo.

Esta definição deveria ser clara e assertiva para facilitar a aplicação. A redefinição das etapas de trabalho foi aprovada por todos os integrantes das equipes e também pelos superiores.

\subsection{1. $1^{\text {a }}$ ETAPA - Revisão do processo}

Primeiramente, foi necessário garantir que a equipe tivesse conhecimentos similares da operação que seria analisada e para que isso fosse possível, foi desenvolvido um fluxograma que descrevia o fluxo do processo completo, ou seja, do início ao fim.

O próximo passo dado foi a identificação de requisitos para cada função do processo que seriam as saídas de cada etapa de processo descrita nos requisitos de produto. Esta identificação foi fundamental para o desenvolvimento da PFMEA.

Após redefinição da equipe através de conhecimentos em PFMEA e nível de comprometimento no treinamento foi necessário manter uma equipe estável durante o desenvolvimento da PFMEA.

\subsection{2. $2^{\text {a }}$ ETAPA - Reunião para definição dos potenciais modos de falha}

A definição de modo de falha potencial é feita através da maneira pela qual um componente ou sistema potencial falharia ao cumprir determinada função destinada a ele. O modo de falha Potencial pode causar também a falha potencial em um sistema ou subsistema de nível superior ou ter um efeito no nível inferior.

Assim, foi elaborada uma lista com cada modo de falha associado a cada item e sua respectiva função. Para que a PFMEA seja realizada é necessário assumir que a falha pode ocorrer, mas não é exato se ela vai ocorrer ou não. Todos os modos de falhas potenciais devem ser considerados.

No início da reunião com as equipes foi feita uma análise crítica de problemas que ocorrerão no passado, verificação de relatórios e então foi feita uma discussão em equipe. Esta discussão só pode ser feita após o treinamento para garantir que todos na equipe tivessem entendimento do 
processo e é feita na forma de brainstorming, de forma a levantar os potenciais modos de falha de cada etapa.

As reuniões seguiram a sequência de processo e todas as informações foram anotadas diretamente no novo formulário de PFMEA para gerar um relatório com ideias de melhoria.

\subsection{3. $3^{\text {a }}$ ETAPA - Listar os potenciais efeitos para cada modo de falha}

Os efeitos do modo de falha na função devem ser definidos pois podem afetar a segurança ou o cumprimento ou não de regulamentos e/ou legislação. Estes efeitos devem ser definidos em termos de sistema ou componente analisado.

Após a listagem dos efeitos do modo de falha para cada etapa de processo no formulário PFMEA, a equipe identificou as consequências caso a falha ocorresse.

\subsection{4. $4^{\text {a }}$ ETAPA - Definir pontuação para severidade de cada efeito}

Severidade (S) é um julgamento do quão sério é um efeito de modo de falha potencial no cliente. O cliente pode ser a próxima etapa de operação, operações subsequentes e até o usuário final.

Existe uma pontuação de severidade que é baseada em uma escala de 10 pontos, sendo que quando menor o número, maior a severidade. Ao fazer a pontuação para severidade se levou em consideração os impactos negativos que o efeito poderia causar para o cliente caso a falha viesse a ocorrer. Foi de extrema importância considerar que cada modo de falha poderia ter diversos efeitos e cada efeito poderia ter diferentes graus de severidade.

\subsection{5. $5^{\text {a }}$ ETAPA - Identificar causa e definir pontuação de ocorrência para cada modo de falha}

Os eventos que geram, provocam e induzem o aparecimento do modo de falha são conhecidos como causa de falha.

Ocorrência (O) é a probabilidade de uma causa específica ocorrer.

Após estas definições, é possível descrever que nesta etapa foram identificadas as causas possíveis para cada modo de falha. Nesta identificação foram utilizadas ferramentas da qualidade.

Nesta etapa também foi definida uma pontuação, só que para cada ocorrência. A pontuação é baseada em uma escada de 10 pontos, sendo 1 o menor índice. Sendo que o melhor método para se definir a pontuação é por meio do histórico de falhas.

\subsection{6. ${ }^{\text {a }}$ ETAPA - Definir pontuação para detecção de cada modo de falha}

Inicialmente nesta etapa foi necessário analisar e identificar os controles atuais do processo que podem ser:

- Prevenção - antecipa-se a ocorrência da causa da falha ou modo de falha.

- Detecção - localizar a causa da falha ou o modo da falha e conduz ao desenvolvimento de ações corretivas ou contramedidas.

Existe também uma pontuação para detecção e ela foi baseada no processo como capaz de identificar a falha ou efeito, em uma escala de 10 pontos. Esta, porém, ao contrário das anteriores, o nível 1 é o de maior detecção.

\subsection{7. $7^{\text {a }}$ ETAPA - Calcular o Grau de Prioridade de Risco para cada modo de falha}

As pontuações de severidade, ocorrência e detecção são utilizadas para calcular o Grau de Prioridade de Risco (RPN). Ou seja, o Grau de Prioridade de Risco é calculado multiplicando-se a pontuação de severidade pela pontuação de ocorrência e também pela pontuação de detecção.

Após a implementação dos planos de ações e ocorrer uma reavaliação de pontuação, os valores obtidos podem vir a ser utilizados no futuro para comparações.

\subsection{8. $8^{\text {a }}$ ETAPA - Priorizar os modos de falha para ação}


O gráfico de Pareto é um dos métodos para se priorizar os modos de falha para ação. Nele, os modos de falha são ordenados do maior número de prioridade de risco para o menor. É utilizado o conceito Pareto 80/20, ou seja, $80 \%$ do total do Grau de Prioridade de Risco provem de apenas $20 \%$ dos potenciais modos de falha.

Em relação a severidade, os modos de falha com pontuação 9 e 10 devem ser automaticamente priorizados, independente do resultado para Grau de Prioridade de Risco.

\subsection{9. $9^{\text {a }}$ ETAPA - Definir ações para eliminar/reduzir os Graus de Prioridades mais elevados}

Foi necessário estabelecer plano de ação que resolvesse os problemas, ou seja, foi necessário identificar, analisar e programar ações que reduzissem ou eliminassem os valores de Grau de Prioridade de Risco.

As ações tomadas com o objetivo de reduzir as pontuações seguiram uma ordem de severidade, ocorrência e detecção.

\subsubsection{0 ${ }^{a}$ ETAPA - Calcular novos resultados de Grau de Prioridade}

As pontuações de severidade, ocorrência e detecção foram reavaliadas após as ações de melhorias planejadas e acompanhamento de resultados serem finalizadas para comprovação de eficácia e consequentemente para recálculo de novo Grau de Prioridade de Risco.

A nova avaliação de Grau de Prioridade de Risco também deve ser organizada em forma de Pareto e comparada com o original. O objetivo é a melhoria contínua. Foi detectada uma redução de $68 \%$ do valor inicial na empresa Alfa.

\subsection{Ganhos mensuráveis}

As ações preventivas e detectivas das não-conformidades no fornecedor geraram a redução na ocorrência das mesmas no recebimento e na linha de montagem. No primeiro semestre de 2018, foram abertas 800 CDs (notas geradas para cada não conformidade) internas, ao custo de US\$100,00 cada. Somando-se ao custo da solução de um técnico para tratar cada CD, totalizou-se US\$137.600,00. Hoje, cada CD custa em média US\$ 50,00. Com a PFMEA, as ações de não-conformidade, além de ocorrerem em menor quantidade, são resolvidas em menor tempo. Com isto, foram abertas $200 \mathrm{CDs}$ internas no primeiro semestre de 2019, gerando uma economia de aproximadamente $90 \%$. Além disso, as não conformidades abertas no fornecedor baixaram de $14.700 \mathrm{CDs}$, no primeiro semestre de 2018, para 3.500 no primeiro semestre de 2019, gerando uma economia de aproximadamente $77 \%$.

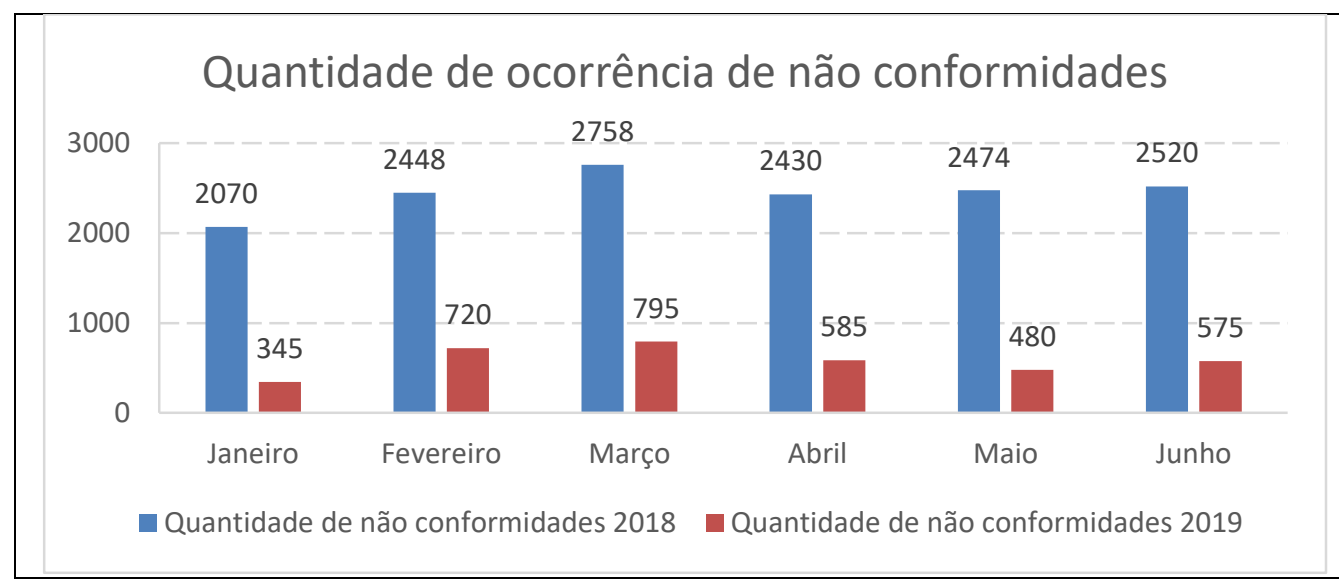

Figura 7. Quantidade de ocorrências de não conformidades no fornecedor antes e depois da implementação do FMEA de Processo

Fonte: Empresa Alfa (2019) 


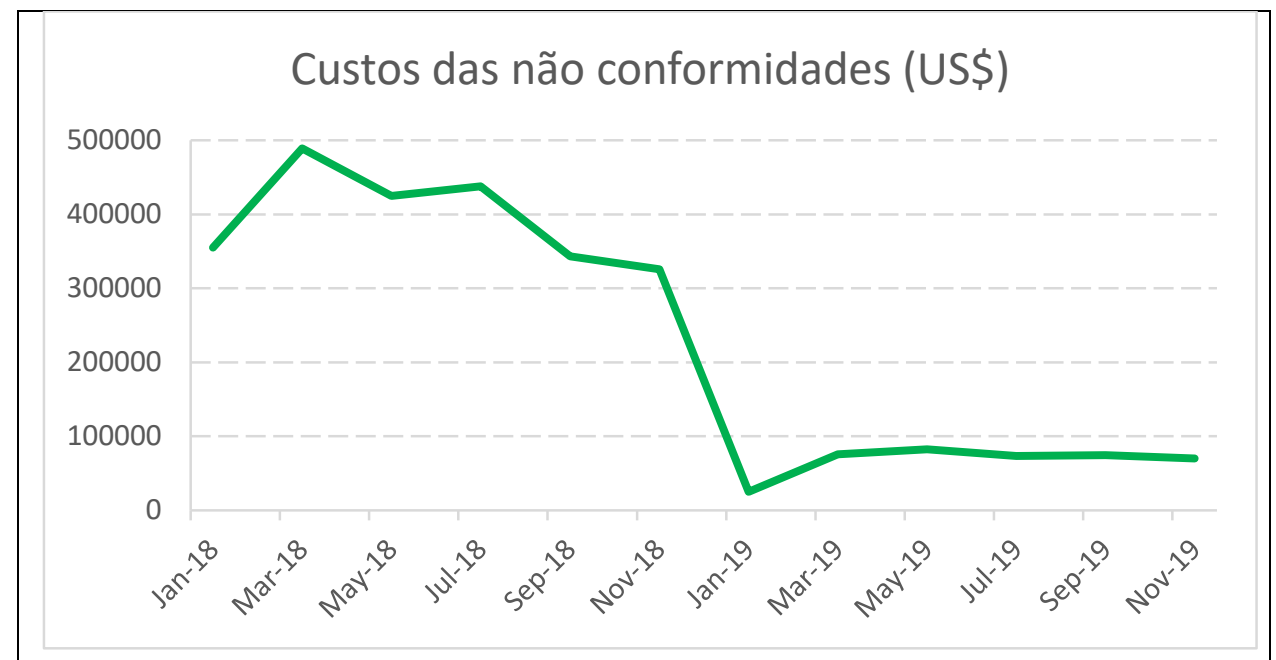

Figura 8. Custo das não conformidades de Jan/15 à Dez/16 em dólares (US\$) Fonte: Empresa Alfa (2019)

\section{CONCLUSÃO}

A PFMEA acumula todas as lições aprendidas relacionadas ao processo, tornando-se assim um banco de conhecimento que poderá ser utilizado em desenvolvimentos futuros e também padroniza as informações do processo produtivo. Além de contribuir para oportunidades de melhoria nos métodos e processos existentes, reduzindo os custos operacionais como retrabalho e atua na prevenção de reclamações e devoluções. Com a consolidação da PFMEA como ferramenta de aprimoramento contínuo da qualidade, a empresa torna-se mais competitiva no mercado, pois é capaz de atender às exigências dos clientes, aumentando assim, suas confiabilidade, qualidade e segurança, além de reduzir custo e tempo no desenvolvimento de processos.

\section{REFERÊNCIAS}

AGUIAR, D. C.; MELLO, C. H. P. FMEA de Processo: Uma Proposta de Aplicação Baseada nos Conceitos da ISO 9001:2000. Disponível em:

<http://www.abepro.org.br/biblioteca/enegep2008_TN_STO_070_501_10838.pdf>.Acesso em: 14 Abr 2019.

CASSANELLI, G. et al. Failure Analysis-assisted FMEA. Microelectronics Reability, v. 46, p. 1795-1799, 2006.

PALADY, P. FMEA: Análise dos Modos de Falha e Efeitos: Provendo e prevenindo problemas antes que ocorram. Tradução Outras Palavras, São Paulo: IMAN, 1997.

SILVA, S. R. Manutenção Centrada na Confiabilidade (MCC) e a Análise de Modos e Efeitos das falhas (FMEA). 2005. 135 f. Monografia (especialização) - Universidade de Taubaté, Departamento de Engenharia Mecânica.

ZORZAN, F. et al. FMEA: Orientações Conceituais para a Aplicação de uma Ferramenta de Antecipação de Falhas, disponível em:

<http://www.fahor.com.br/publicacoes/sief/2013/FMEA_orientacoes.pdf>. Acesso em: 25 Abr 2019. 